\title{
Akt Fas to Quell Aberrant T Cell Differentiation and Death in Covid-19
}

\author{
Anthony J. Leonardi ${ }^{1}$ and Rui B Proenca ${ }^{2}$ \\ ${ }^{1}$ Other \\ ${ }^{2}$ Johns Hopkins University, Baltimore, Maryland. USA. \\ * Correspondence: \\ Anthony J. Leonardi \\ aleona10@alumni.jh.edu
}

Keywords: AKT, FAS, Covid-19, T-cells, Differentiation, Apoptosis, Lymphopenia

\begin{abstract}
Aberrant $\mathrm{T}$ cell differentiation and lymphopenia are hallmarks of severe COVID-19 disease. Since $T$ cells must race to cull infected cells, they are quick to differentiate and achieve cytotoxic function. With this responsiveness, unfortunately, comes hastened death, due to a coupled mechanism of death and differentiation in both CD4+ and CD8+ lymphocytes via CD95 (Fas) and serine-threonine kinase (Akt). T cell lymphopenia in severe cases may represent cell death or peripheral migration. These facets depict SARS-Cov-2 as a lymphomanipulative pathogen; it distorts $\mathrm{T}$ cell function, numbers, and death, and creates a dysfunctional immune response. Whether preservation of T cells, prevention of their differentiation, and expansion of their population may alter disease course is unknown. Its investigation requires experimental interrogation of the linked differentiation and death pathway by agents known to uncouple $\mathrm{T}$ cell proliferation and differentiation in both CD4+ and CD8+ T cells.
\end{abstract}

\section{Introduction}

An alarming feature of infection identified early in the pandemic was a relative lymphopenia in patients shown to correlate with poor outcomes (1-4). Whether this was due to direct viral infection, activation-induced cell death, or migration to the periphery remains unknown. Indeed, severe Covid-19 is associated with significant lymphocyte hyperactivation, organ infiltration, and tissue damage, suggesting widespread and perhaps, deleterious immune activity. T-cell differentiation and collapse can be facilitated by the canonical death receptor CD95 and interestingly, Bellesi et al. describe the increased expression of CD95 and PD-1 on the T lymphocytes of Covid-19 patients and suggest it could predispose T cells to apoptosis and exhaustion (5). Here, we explore the implications of targeting lymphocyte death and differentiation in Covid-19 via Fas/Akt, and we propose that CD95 may not only serve as a functional marker for apoptosis, but also a means of exuberant differentiation culminating in cytotoxic function, and this expression may represent a therapeutic point of intervention.

\section{Discussion}

\section{Alternative Hypotheses to the "cytokine storm" needed}

The immune dysfunction in Covid-19 has been so far enigmatic. At first, focus was on the elevation of cytokines characteristic of the innate immune compartment (a "cytokine storm") 
associated with severe Covid-19, including IL-6, IL-8, and IL-10, among others $(3,4,6,7)$. However, a meta-analysis showed IL-8 and IL-10 were substantially lower in Covid-19 as compared to conditions like cytokine release syndrome, Acute Respiratory Distress Syndrome, and Sepsis (7). The authors suggest the attribution of a "cytokine storm" to Covid19 pathogenesis was questionable (7). In a randomized trial, IL-6 blocking therapy was unfortunately noted to be of little therapeutic benefit in hospitalized patients (9). Based on their findings, Leisman, et al. call for alternative hypothetical mechanisms explaining the level of organ damage and immunopathology (7). One consistency they note, however, is the preponderance of a lymphopenia in cases of severe Covid-19 (7).

\section{1) Dissecting "exhaustion" and end organ damage in Covid-19}

A key question is whether the lymphopenia is a mere marker of worsening disease or is a mechanistic component where intervention could influence outcomes. Diao, et al. and Wang, et al. note decreases in CD4+ and CD8 $+\mathrm{T}$ cells $(10,11)$, and Wang, et al. show in a multivariate analysis that posttreatment decreases in CD8+ T cells, B cells, and an increased CD4+/CD8+ ratio were independent predictors of poor outcomes (11). Another study by Moderbacher, et al. describe a causal relationship of the presence of naïve CD8+ T cells, and claimed that in acute and convalescent cases of Covid-19, peak disease severity was associated with a lack of naïve CD8 $+\mathrm{T}$ cells and suggested the relationship may be causal by virtue of less proliferative and responsive capacity (12). Diao, et al. also noted elevated PD-1 and TIM-3 expression on CD8+ T cells in recovering patients and proposed the cells may be exhausted in latter stages of disease, with CD4+ cells showing elevated PD-1 expression in worsening disease (10). Zheng, et al. noticed a kinetic where the total number of Natural Killer (NK) cells and CD8+ T cells would decrease with worsening disease, and upregulate the marker of exhaustion NKG2A, but they claim with successful treatment with lopinavirritonavir the counts would then increase and NKG2A expression would decrease during the convalescent period (13). Zheng, et al. did not find lymphopenia in their cohort, however they noted that a non-exhausted subgroup of PD-1- CTLA4- TIGIT-CD8+ T cells were significantly reduced in percentage in patients with severe Covid-19 compared to mild and moderate (14). Westmeier, et al. sought to characterize the proteins that cause cytotoxicity and possibly immunopathological organ damage, and found in young (29-79) patients, CD8+ $\mathrm{T}$ cells activated ex vivo following convalescence produced granzymes $\mathrm{A}, \mathrm{B}$, and perforin at greater levels than healthy donors despite expressing PD-1, suggesting the exhaustion was not functional despite PD-1 expression (15). However, the CD8+ T cells of the elderly group (ages 80-96) did not upregulate the cytotoxic markers Granzyme B and Perforin as the younger group did (ages 29-79), indicating an age-related exhaustion (15). They conclude PD-1 expressing CD8+ cells should not be 'misclassified' as exhausted, however they state that PD-1 therapy may improve virus control (presumably in the elderly group) but also may "exaggerate the immunopathology in the lungs and other organs" (15). We agree with this therapy in regard to aged patients but also propose that cytotoxic function may be overexuberant in younger populations, and that withholding differentiation may, to an extent, temper Granzyme and Perforin expression. Ueland, et al. recapitulate the findings by Diao, et al. and report that sTIM-3, an exhaustion marker associated with chronic infections including HIV, Hepatitis B, Hepatitis C, and pulmonary tuberculosis, had a rise in expression in severe (ICU) patients, which correlated with the measured degree of pulmonary infiltration and the cardiac marker NTproBNP (16). Ueland, et al. hypothesize that T cells are traveling to these organs and are responsible for their harm, but temporarily upregulate sTIM-3 as "a mechanism to prevent persistent and overshooting T-cell activation, which could harm the host" (16). They still, however, claim their findings suggest that T-cell activation and exhaustion play a role in Covid-19 and posit T-cell targeted treatment options may be of 
interest (16). Varchetta, et al. report an increase in TIM-3 and CD69 expression in CD8+ T cells and note the extent of CD8+ T cell lymphopenia was significantly greater in patients that succumbed to Covid-19 (17). They describe this as a hyperactivated/ exhausted state, and observed that during recovery TIM-3 and CD69 expression on T cells fell and CD8+ lymphocyte count rose, and offer TIM-3, PD-1, and NKG2A as "druggable molecules" that may be used to "unleash antiviral activity" (17).

In an autopsy series, Nienhold, et al. describe two "immunopathological reaction patterns" (18). The first is characterized by lung infiltration of CD8+ PD1+ T cells that they speculate are causing diffuse alveolar damage (DAD) but better viral control, and they question whether the PD-1 positivity denotes exhaustion, but no conclusions are drawn. The other immunopathological pattern is characterized by significantly higher CD4+ T cell lung infiltrates and a higher viral load (18). They conclude this suggests CD8+ T cells indeed contribute to viral clearance but may exert a degree of end organ damage (18). Schurink, et al. found either one of two types of T cell infiltration in all autopsies: a CD8+ infiltrate causing DAD, or a CD4+ interstitial infiltrate with exudative diffuse alveolar damage and bronchopneumonia (19).

\section{2) Too many Licenses to Kill}

Multiorgan tissue damage is present in severe cases of Covid-19 and Multisystem Inflammatory Syndrome in Children, (MIS-C), possibly contributed to by T cells activated by a superantigenic-like insert (20). After activation, such T cells may be capable of migration to peripheral tissues following their differentiation and acquisition of cytotoxic ability conferred by effector differentiation (20). Cheng, et al. argue that by virtue of the superantigenic insert, infection would prime self-reactive T cells (20). Combined with the apparent downregulation of FOXP3 in CD4+ CD25+ T Cells and their expression of FASL in Covid-19 patients (21), this could bode poorly for organs and immune-privileged sites. Following Covid-19 even canonically immune-privileged sites like the eye have inflammatory infiltrates (22) along with organs like the heart (23). Israelow, et al. observe hyperactivation of CD8+ cells and their infiltration into the lung in a murine model of Covid-19 (24). Indeed, an increase in the frequency of effector cells has been shown in one analysis of $\mathrm{T}$ cell physiological correlates of Covid-19 disease severity; CD8+ T cells in severe cases expressed greater levels of Granzyme and Perforin than in patients with mild disease (16), but whether this represents increased effector function or a marker for exhaustion in Covid-19 is unknown considering that in the Covid-19 disease state since Kalfaoglu, et al. show even PD-1 was not inducing lymphocyte exhaustion (21). Taken with the recent findings discussed previously, we propose testing the alternative hypothesis but forward by Westmeier, et al, that the expression of granzyme and perforin may engender greater end organ damage by virtue of their function (15). These insights and observations suggest exuberant activation in Covid-19 may facilitate differentiation of T cells. Overexuberant acquisition of effector function may be targeted through CD95's nonapoptotic signal via AKT (32).

\section{3) Evidence of absence (via hyperactivation and perhaps death)}

Zinzula describes the crucial role of the type I interferon responses in Covid-19 in respect to the ORF8 protein (25). When this protein, which downregulates MHC I, is ablated with the frameshift mutation $\Delta 382$, patients experience mild illness (25). In a study of patients with the mutation, Young et al. find these patients exhibit higher levels of IFN- $\gamma$, TNF- $\alpha$, IL-2, and IL-5, which they contextualize as associated with T cell activation (26). Habel, et al. describe an irreconcilable amount of CD8+ "bystander activation ... by some mechanism" and also observe, in convalescence, a paucity of circulating effector subsets, and describe it as either 
due to 1) limited clonal expansion and differentiation or 2) T cell effectors are being driven to sites of virus-induced pathology and driven to apoptosis (27). In transcriptome analysis Zhang, et al. found that the CD8+ naïve T cell subset did not restore to the levels of healthy donors in convalescence, and that a subset of CD8+ effectors expressing GNLY, had highly cytotoxic function, became high and remained high even in convalescence (28). Furthermore, using Gene Set Ontology, they found statistically significant, stepwise increases in the programs for 1) apoptosis and 2) migration in T cells from patients with Covid-19 (healthy donor/moderate/severe), which led them to conclude "T cells in severe patients likely underwent migration and apoptosis" (28). Taken together with the proposed presence of a superantigenic-like insert by Cheng, et al, we propose that attenuation of the honest expression of MHC I by ORF8 may allow superantigenic accumulation to a point as to when the adaptive compartment is finally presented antigen, there is an atypically massive viral protein and superantigenic burden in the pipeline which may hyperstimulate, lead to AICD, overexuberant differentiation, tissue migration (as per the alternative hypothesis put forth by Habel, et al.), and cytotoxic function. Indeed, De Biasi, et al. find a production and release of cytokines they describe as similar to "a polyclonal, superantigen-driven T-cell activation" and observed increased levels of IFN- $\gamma$ in the plasma of Covid-19 patients (29). They also noted the increased expression of CD57 on CD8+ T cells of Covid-19 patients, which they claim denotes a susceptibility to activation-induced cell death and a lack of proliferative capacity (29), However, Focosi, et al. note there is preservation of cytokine secretion after stimulation of CD57+ lymphocytes (30). Furthermore, Chattopadhyay et al. have noted CD8+ T cells “expressing high levels of Perf were uniformly bright for CD57" (31).

With the findings by Bellesi, et al, of increased CD95 expression, we believe there may be a contributing element of apoptosis to the lymphopenia observed in Covid-19, but this is a challenge to prove as cells which apoptose by this mechanism do not remain for functional read-outs. Withholding differentiation may 1) reduce the expression of the cytotoxic proteins like granzyme and perforin that Westmeier, et al theorize contribute to end organ damage; 2) maintain CD62L expression and other functional markers associated with less differentiation which may keep T cells from peripheral migration; and 3) prevent CD95-mediated death, which has been shown to predominantly occur in differentiated effector memory lymphocytes rather than naïve, stem cell memory, and central memory subsets of differentiation (32).

\section{Aberrant CD4+ T cell Differentiation in Covid-19}

Aberrant effector differentiation has been described in CD4+ T cells in severe cases of Covid-19 as well (21). Kalfaoglu, et al. describe an aberrantly differentiated subset of CD4+ CD25+ FOXP3- T cells they call "hyperactivated T-cells" which become multifaceted Th1Th2 effector cells rather than Tregs due to the repressed expression of FOXP3 (21). These CD4+ CD25+ T cells 'vigorously' proliferate, downregulate FOXP3, and express FASL in a dysfunctional differentiation pathway induced by Covid-19 (21). The authors also state the CD25+ "hyperactivated T-cells" also expressed PD-1, but noted it was not able to control or suppress their function and hypothesize CD80 may be suppressing PD-1 function (21). We would like to bring this insensitivity to exhaustion in context to the observations and assumptions of exhaustion in studies cited previously. Such insensitivity to PD-1 in these aberrant cells represents exuberant function, and the FasL expression may represent a liability. For example, FasL expression on CD8+ T cells is known to confer a paracrine T-cell fratricidal liability in vivo (33), and a paracrine T-cell to T-cell FasL-Fas signal was also shown to exert precocious differentiation of naïve CD8 $+\mathrm{T}$ cells by concurrently stimulated effector memory CD8 + T cells in an effect that was mitigated by a FasL blocking antibody (32). Much like their CD8+ counterparts, Non-apoptotic signaling of Fas differentiates 
murine CD4+ T cells as well (34); Cruz, et al. show that LZ-FasL treatment during in vitro stimulation of CD4+ cells enhances differentiation from naïve to CD44 ${ }^{\text {hi }}$ CD62L ${ }^{\text {lo }}$ effector memory for wild type CD4+ T cells (34). Differentiation was induced in Fas palmitoylationdeficient (C194V) cells, (which are replete in non-apoptotic Fas signalling but have a palmitoylation defect which prevents the apoptotic signal of Fas and therefore the apoptosis) but not for CD4+ lpr cells which are completely deficient in Fas signaling (34). Additionally, non-apoptotic signaling of Fas has been shown to reduce the frequency of FOXP3+ CD4+ Tregs in mice (34). lpr mice completely deficient in Fas signaling were crossed to express a version of Fas that was replete in non-apoptotic signalling but that had a palmitoylation defect $(\mathrm{C} 194 \mathrm{~V})$ which prevents the apoptotic signal of Fas, and had a decrease in Tregs from higher frequency of that in lpr alone, to a normal/ near wild-type frequency, which may suggest non-apoptotic Fas signalling in vivo may reduce the frequency of FOXP3 expressing CD4+ cells (34). Furthermore, Akt signaling in human CD4+ T cells has been shown to repress FOXO1- a key transcription factor that enables FOXP3 expression and function (34, 35). Much like their CD8+ counterparts, CD4+ T cells also have effector differentiation withheld following stimulation with an AKT inhibitor (37) in addition to the retention of functional FOXO1 (38). It seems warranted to test whether FOXP3 expression can be maintained by inhibition of the Fas/AKT pathway in the Covid-19 disease state.

\section{CD95 sensitivity following activation leading to differentiation}

In parallel with lymphopenia in severe cases of Covid-19, the machinery responsible for $\mathrm{T}$ cell death and differentiation are enriched as well. Bellesi, et al. showed CD-95 was highly expressed on the T cells of Covid-19 patients (5) and Mathew, et al. identify CD95 as a marker of aberrant CD8+ cells in an 'immunotype' associated with severe Covid-19 (39). Both the expression of CD95 on T cells and the sensitivity to CD95 stimulation are rapidly inducible through $\mathrm{T}$ cell activation (32), and Cheng, et al. argue $\mathrm{T}$ cells are activated by a superantigenic motif on the Spike protein of SARS-Cov-2 that is highly similar to staphylococcal enterotoxin B (20). Activated T cells are especially sensitive to the CD95mediated differentiation signal (32), and interestingly, a non-apoptotic CD95 signal was shown to cause differentiation and effector function in activated (CD3/CD28 stimulated) murine and human CD8+ T-cells in a dose-dependent manner with leucine zipper tagged Fas ligand (LZ-FasL), and this differentiation signal was carried through AKT (32). Interestingly, the death induced by trimerized CD95 Ligand (CD95L/CD178) was shown to be predominantly limited to the terminally differentiated cells rather than the Naïve and Central Memory (32). Furthermore, death and differentiation were withheld during in vitro stimulation and expansion of T cells by use of an AKT inhibitor even in the presence of LZFasL, revealing a dominant effect of AKT inhibition for the mitigation of CD95 signalling (32). Considering this mechanism of widespread activation, T cells not specific to SARSCOV-2 may differentiate, achieve expression of functional cytotoxic proteins, and die, possibly via a CD95 mediated component.

\section{Who will be the first to Akt?}

Akt inhibition as a potential therapeutic for Covid-19 has been proposed in the past. Fagone, et al. describe a transcriptomic profile in which Akt signaling was associated with disease progression (40), and Somanath discusses a similar rationale of modulating immunemediated inflammation: that Akt inhibition is justified on the basis of an anti-inflammatory effect exerted by CD4+ T cells that may differentiate into Effector T regulatory cells in the ARDS lung (41). While we concur, we would like to supplement this argument further with discussion of the effects on the differentiation and acquisition of effector function and the inclusion of nonapoptotic CD95 signaling upstream. Akt inhibition has also been proposed on 
the basis of an anti-viral effect (42-44). However, it appears that in presenting stages of Covid-19 disease antiviral agents seem to have questionable therapeutic benefit, possibly due to the disease entering an immunopathological stage of exuberant lymphocytic response (23). Sorbera, et al. claim SARS-Cov-induced apoptosis via a caspase-dependent mechanism may suggest inhibition of the FasL/Fas interaction may have efficacy in Sars-Cov-2, but the rationale disregards differentiation (45). Considering 1) the role the immune system may have in the pathogenesis of Covid-19,2) the observation that FasL is upregulated and 3) that Fas signaling may induce Akt activity and differentiation, leads us to believe the pathway warrants experimental enquiry.

\section{Physiological Type I Interferons required: aetiology of subsets of Covid-19 disease}

While we propose the attenuation of an exuberant effector differentiation may dampen end organ damage, there is a caveat to the general application of this proposed mechanism that requires nuance in the diagnosis and management of patients with distinct aetiologies. Lee and Shin discuss the heterogeny of type I interferon responses and attribute the cause of such discrepancies as due to timing of the observations (early vs. late) and severity of disease (mild/moderate/severe) (46). They propose a feed-forward mechanism found by Lee, et al. where Type I IFNs break a tolerance induced by TNF (47). Lee, et al. posit that an early IFNI response can control viral replication, but a delayed response can cause pathological inflammation (47). Indeed, a deficit in interferon can permit high levels of detectable virus in the blood (48). Illustrating this heterogeneity, Lee and Shin cite a trial which found administered IFN $\alpha$ had a protective effect if given early and a detrimental effect if given late $(46,49)$. Furthermore, Bastard, et al. describe individuals predisposed to severe Covid-19 with autoantibodies against type I interferons representing about $10 \%$ of a cohort of severe patients (50), and Zhang, et al. identify inborn errors of Interferons (including TLR3, IFNAR1, and IFNAR2) in 3.5\% of patients in a cohort with life-threatening Covid-19 (51). We believe studying the role of CD95 in a murine model of Covid-19 without such inborn or acquired errors may not recapitulate the autoantibody or inborn errors of IFN seen in a subset of patients but would rather be more comparable to the pathological experience in a patient without such inborn defects in Interferon or autoantibody responses. We cannot comment on the $\mathrm{T}$ cell kinetics or differentiation states of such patients, as insufficient data exists, however Zhang, et al. propose it would be helpful to identify such patients early or even before infection so they may have their deficiencies supplemented with Interferon when an efficacious therapy is found (51).

\section{Mitigating the $T$ cell physiological consequences of Covid-19}

CD4+ and CD8+ T cells post Covid-19 were on the whole, less comprised of naïve and memory subsets in survivors vs. healthy donors, while the former had a lesser proportion of naïve cells on a background of lymphopenia (52). When taking this finding from Yang, et al. of diminished proportion of Naïve CD4+ and CD8+ T cells post- Covid-19 (52) along with the finding from Moderbacher, et al. that naïve CD8+ T cells are associated with lesser disease severity (12), we must consider the consequences of reinfection if the pool of naïve $T$ cells significantly diminishes after infection and outcomes are influenced by the presence of naïve CD8+ T cells. In this scenario, it would be best to preserve lesser-differentiated populations of T cells by blocking CD95-mediated T-cell death and differentiation in vivo, which is precedented in a murine-human xenograft model of CAR-T adoptive immunotherapy; CAR-T cells transduced with a recombinant FAS receptor lacking an intracellular signalling domain were substantially more capable of inducing durable tumor responses and showed increased in vivo persistence, presumably by virtue of their attenuated differentiation and death (53). Also, blocking T cell effector acquisition in vitro during TCR 
stimulation and expansion with a CD95 blocking antibody or with an AKT1/AKT2 (AKT VIII) inhibitor, has been shown to allow tumor-specific CD8+ T cells to proliferate without differentiating, thereby greatly increasing their numbers and withholding premature apoptosis (32). Furthermore, on a cell-for-cell basis, T cells with their differentiation withheld by AKT inhibition were superior at eradicating established human and murine tumor after adoptive transfer in both a murine and murine-human xenograft models of adoptive $\mathrm{T}$ cell immunotherapy $(32,37,38)$. AKT inhibition also maintained a higher percentage of CD62L+ CD44- CD8+ T cells (Tn or Tscm) after stimulation, and Fas signaling induced with LZFasL, a trimerized CD95 ligand, differentiated naïve T cells in a dose-dependent fashion (32). While we are aware that stimulation and expansion in vivo vs. ex vivo are entirely different contexts, we propose the differentiation and death signal and susceptibility of T cells to CD95 is similar. It would be advisable to further characterize the effect in vivo.

\section{Exploring CD95's Possible Dual Action of Death and Differentiation in Covid-19}

The role of an AKT-mediated CD95 signal as a causal factor rather than a marker in this aberrancy warrants further exploration since CD95 could be implicated twofold: not only in the death of the T cells, but also in the exuberant effector differentiation seen in severe cases of Covid-19 via AKT (54). Given the dual function of CD95, it seems possible that CD95mediated differentiation and death may be advancing $\mathrm{T}$ cells to greater effector acquisition, fewer numbers, and immune dysregulation, and that this may be a pathological state yielding tissue damage due to superantigenic stimulation of T cells not specific to SARS-Cov-2. The possibility CD95-mediated death and differentiation are pathogenic can be tested in murine models of severe/lethal Covid-19, like the K18 hACE2 model (55). Also, it is possible the effects of Fas modulation have been indirectly manifest in a non-randomized prospective trial of GM-CSF blockade in Covid-19 patients (56). In a CRISPR-Cas9 lentiviral vector knock out of GM-CSF in CAR T cells, FAS expression was significantly inhibited, which the authors argue would reduce CAR-T apoptosis (57). In a non-randomized study of admitted Covid-19 patients, an antibody blocking GM-CSF yielded a significant reduction in Covid-19 progression (56). The authors argue GM-CSF blockade acts on the IL-6 pathway (56), but recent trials show targeting IL-6 in Covid-19 does not yield a benefit (9). Therefore, it is a possibility that GM-CSF inhibition may have an effect on Covid-19 treatment by virtue of reduced CD95 expression on T cells rather than modulation of IL-6. We advise preliminary investigation in an animal model in order to understand the potential role of $\mathrm{T}$ cell differentiation and death and the effects of its modulation in different phases of Covid-19, as in some stages it may be deleterious, and a simple lack of efficacy is not the worst-case scenario. For example, there is a possibility that death may be the best option for peripherally migrated $\mathrm{T}$ cells with established cytotoxic function, and that preventing it may potentiate $\mathrm{T}$ cell mediated end-organ damage, although it is unknown how readily such $\mathrm{T}$ cells die and how this differs among patient populations.

\section{"B" cautious regarding $B$ cell differentiation}

A level of prudent caution is advised in the investigation of Akt and Cd95's role in Covid-19 due to the role of competent Fas signaling in prevention of B cell mediated autoimmunity in germinal-center B cells (58). Although, in severe cases of Covid-19, extrafollicular B cells may differentiate into effector B cells that lack CXCR5 and CD21, and are correlated with more severe Covid-19 with a B cell phenotype the group previously found in Lupus (59). Jenks, et al. showed a Gene Set Enrichment Analysis revealing B cells that correlate with SLE severity possess a transcriptome also enriched in gene sets from effector memory $\mathrm{T}$ cells (60). Notably, Woodruff, et al. postulate this phenotype in Covid-19 is dependent on TLR7 signaling (59), which has been shown to signal through Akt/mTOR (61). TLR7-mediated 
CD25, CD44, and CD69 expression can be significantly reduced in CD8+ T cells when Akt inhibitor is present (61). Therefore, if these signaling pathways are comparable between $\mathrm{B}$ and $\mathrm{T}$ cells, Akt inhibition may attenuate the autoimmune extrafollicular B cell effector differentiation seen in Covid-19.

\section{Conclusion}

The mechanism of lymphocyte collapse by Covid-19 may be in part by rapid differentiation and peripheral migration or death of lymphocytes from CD95 agonization following their activation. The preservation of the population subject to this component, along with the prevention of their effector differentiation and widespread pyroptosis, may help attain the goals of 1) both functional capacities of directly killing cells that harbor virus with these CD8+ T-cells, and 2) preventing highly differentiated and cytotoxic T cell activity in peripheral tissues by virtue of a single therapeutic. It is critical, however, that such an intervention be taken early; for this lymphopenia correlative of poor outcomes is observed well beforehand. Preclinical animal models of severe Covid-19 that recapitulate a type I interferon competent and lymphopenic experience may be useful for the investigation of a strategy which seeks to preserve $T$ cells and reduce their dysfunction by preventing differentiation and death.

\section{Conflict of Interest}

The author has filed a patent application pertaining to the methods described in this manuscript.

\section{Author Contributions}

AJL wrote the first draft and revision. RBP discussed the evidence and literature and edited the manuscript.

\section{Funding}

The work was not supported by external sources of funding.

\section{Acknowledgments}

Giles Bradshaw noted relevant references.

\section{Dedication}

This work is dedicated to Alvin E. Marcus.

\section{References}

1. Chen N, Zhou M, Dong X, et al. Epidemiological and clinical characteristics of 99 cases of 2019 novel coronavirus pneumonia in Wuhan, China: a descriptive study. Lancet. (2020) 395(10223):507-513. doi:10.1016/S0140-6736(20)30211-7 
2. Tan L, Wang Q, Zhang D, et al. Lymphopenia predicts disease severity of COVID-19: a descriptive and predictive study. Signal Transduct Target Ther. (2020) 5(1):33. doi:10.1038/s41392-020-0148-4

3. Li S, Jiang L, Li X, Lin F, Wang Y, Li B, Jiang T, An W, Liu S, Liu H, Xu P, Zhao L, Zhang L, Mu J, Wang H, Kang J, Li Y, Huang L, Zhu C, Zhao S, Lu J, Ji J, Zhao J. Clinical and pathological investigation of patients with severe COVID-19. JCI Insight. 2020 Jun 18;5(12):e138070. doi: 10.1172/jci.insight.138070.

4. Shi H, Wang W, Yin J, Ouyang Y, Pang L, Feng Y, Qiao L, Guo X, Shi H, Jin R, Chen D. The inhibition of IL-2/IL-2R gives rise to CD8+ T cell and lymphocyte decrease through JAK1-STAT5 in critical patients with COVID-19 pneumonia. Cell Death Dis. 2020 Jun 8;11(6):429. doi: 10.1038/s41419-020-2636-4.

5. Bellesi S, Metafuni E, Hohaus S, et al. Increased CD95 (Fas) and PD-1 expression in peripheral blood T lymphocytes in COVID-19 patients. Br J Haematol. (2020) 10.1111/bjh.17034. doi:10.1111/bjh.17034

6. Remy KE, Mazer M, Striker DA, Ellebedy AH, Walton AH, Unsinger J, Blood TM, Mudd PA, Yi DJ, Mannion DA, Osborne DF, Martin RS, Anand NJ, Bosanquet JP, Blood J, Drewry AM, Caldwell CC, Turnbull IR, Brakenridge SC, Moldwawer LL, Hotchkiss RS. Severe immunosuppression and not a cytokine storm characterizes COVID-19 infections. JCI Insight. 2020 Sep 3;5(17):e140329. doi: 10.1172/jci.insight.140329.

7. Leisman DE, Ronner L, Pinotti R, Taylor, MD, Sinha P, Calfee CS, Hirayama AV, Mastroiani F, Turtle CJ, Harhay MO, Legrand M, Deutschman CS. Cytokine elevation in severe and critical COVID-19: a rapid systematic review, meta-analysis, and comparison with other inflammatory syndromes. Lancet Respir Med. (2020) doi.org/10.1016/S22132600(20)30404-5

8. Nagant C, Ponthieux F, Smet J, Dauby N, Doyen V, Besse-Hammer T, De Bels D, Maillart E, Corazza F. A score combining early detection of cytokines accurately predicts COVID-19 severity and intensive care unit transfer. Int J Infect Dis. 2020 Oct 8:S1201-9712(20)32206-2. doi: 10.1016/j.ijid.2020.10.003.

9. John H. Stone, M.D., M.P.H., Matthew J. Frigault, M.D., Naomi J. Serling-Boyd, M.D., Ana D. Fernandes, M.A., Liam Harvey, B.S., Andrea S. Foulkes, Ph.D., Nora K. Horick, M.S., Brian C. Healy, Ph.D., Ruta Shah, M.D., Ana Maria Bensaci, M.D., Ann E. Woolley, M.D., Sarah Nikiforow, M.D., Ph.D., et al., for the BACC Bay Tocilizumab Trial Investigators* Efficacy of Tocilizumab in Patients Hospitalized with Covid-19. NEJM (2020) October 21, 2020 doi: 10.1056/NEJMoa2028836

10. Diao B, Wang C, Tan Y, Chen X, Liu Y, Ning, Chen L, Li M, Liu Y, Wang G, Yuan Z, Feng Z, Zhang Y, Wu Y, Chen Y. (2020). Reduction and Functional Exhaustion of T Cells in Patients With Coronavirus Disease 2019 (COVID-19). Front Immunol, 11, 827. doi.org/10.3389/fimmu.2020.00827

11. Wang F, Nie J, Wang H, Zhao Q, Xiong Y, Deng L, Song S, Ma Z, Mo P, Zhang Y. Characteristics of Peripheral Lymphocyte Subset Alteration in COVID-19 Pneumonia. J 
Infect Dis. 2020 May 11;221(11):1762-1769. doi: 10.1093/infdis/jiaa150. PMID: 32227123; PMCID: PMC7184346.

12. Moderbacher CR, Ramirez SI, Dan JM, Grifoni A, Hastie KM, Weiskopf D, Belanger S, Abbott RK, Kim C, Choi J, Kato Y, Crotty EG, Kim C, Rawlings SA, Mateus J, Victor Tse LP, Frazier A, Baric R, Peters B, Greenbaum J, Saphire EO, Smith DM, Sette A, Crotty S, Antigen-specific adaptive immunity to SARS-CoV-2 in acute COVID-19 and associations with age and disease severity, Cell (2020), doi:10.1016/j.cell.2020.09.038.

13. Zheng M, Gao Y, Wang G, Song G, Liu S, Sun D, Xu Y, Tian Z. Functional exhaustion of antiviral lymphocytes in COVID-19 patients. Cell Mol Immunol. 2020 May;17(5):533535. doi: 10.1038/s41423-020-0402-2.

14. Zheng HY, Zhang M, Yang CX, et al. Elevated exhaustion levels and reduced functional diversity of $\mathrm{T}$ cells in peripheral blood may predict severe progression in COVID-19 patients. Cell Mol Immunol. (2020) 17(5):541-543. doi:10.1038/s41423-020-0401-3

15. Westmeier J, Paniskaki K, Karaköse Z, Werner T, Sutter K, Dolff S, Overbeck M, Limmer A, Liu J, Zheng X, Brenner T, Berger MM, Witzke O, Trilling M, Lu M, Yang D, Babel N, Westhoff T, Dittmer U, Zelinskyy G. Impaired Cytotoxic CD8+ T Cell Response in Elderly COVID-19 Patients. mBio. 2020 Sep 18;11(5):e02243-20. doi: 10.1128/mBio.0224320. PMID: 32948688; PMCID: PMC7502863.

16. Ueland T, Heggelund L, Lind A, Holten AR, Tonby K, Michelsen AE, Jenum S, Jørgensen MJ, Barratt-Due A, Skeie LG, Nordøy I, Aanensen Fraz MS, Quist-Paulsen E E, Pischke SE, Johal SK, Hesstvedt L, Bogen M, Fevang B, Halvorsen B, Müller F, Bekken GK, Mollnes TE, Dudman S, Aukrust P, Dyrhol-Riise AM, Holter JC. Elevated plasma sTIM-3 levels in patients with severe COVID-19. J Allergy Clin Immunol. 2020 Sep 21:S0091-6749(20)31314-2. doi: 10.1016/j.jaci.2020.09.007.

17. Varchetta S, Mele D, Oliviero B, Mantovani S, Ludovisi S, Cerino A, Bruno R, Castelli A, Mosconi M, Vecchia M, Roda S, Sachs M, Klersy C, Mondelli MU. Unique immunological profile in patients with COVID-19. Cell Mol Immunol. 2020 Oct 15:1-9. doi: 10.1038/s41423-020-00557-9.

18. Nienhold R, Ciani Y, Koelzer VH, Tzankov A, Haslbauer JD, Menter T, Schwab N, Henkel M, Frank A, Zsikla V, Willi N. Two distinct immunopathological profiles in autopsy lungs of COVID-19. Nature communications. 2020 Oct 8;11(1):1-3.

19. Schurink B, Roos E, et al. Viral presence and immunopathology in patients with lethal COVID-19: a prospective autopsy cohort study. Lancet Microbe. (2020) Jul;1(3):e93. doi: 10.1016/S2666-5247(20)30073-2.

20. Cheng MH, Zhang S, Porritt RA, Rivas MN, Paschold L, Willscher E, Binder M, Arditi M, Bahar I. Superantigenic character of an insert unique to SARS-CoV-2 spike supported by skewed TCR repertoire in patients with hyperinflammation. Proc Natl Acad Sci U S A. (2020) doi.org/10.1073/pnas.2010722117

21. Kalfaoglu Bahire, Almeida-Santos José, Tye Chanidapa Adele, Satou Yorifumi, Ono Masahiro. T-Cell Hyperactivation and Paralysis in Severe COVID-19 Infection Revealed by 
Single-Cell Analysis. Frontiers in Immunology. (2020)

http://doi.org/10.3389/fimmu.2020.589380

22. Bakhoum MF, Ritter M, Garg AK, Chan AX, Bakhoum CY, Smith DM. Subclinical ocular inflammation in persons recovered from ambulatory COVID-19. MedRxiv. (2020) doi.org/10.1101/2020.09.22.20128140

23. Schurink B, Roos E, et al. Viral presence and immunopathology in patients with lethal COVID-19: a prospective autopsy cohort study. Lancet Microbe. (2020) Jul;1(3):e93. doi: 10.1016/S2666-5247(20)30073-2.

24. Israelow B, Song E, Mao T, et al. Mouse model of SARS-CoV-2 reveals inflammatory role of type I interferon signaling. J Exp Med. (2020) 217(12):e20201241.

doi:10.1084/jem.20201241

25. Zinzula L. Lost in deletion: The enigmatic ORF8 protein of SARS-CoV-2. Biochem Biophys Res Commun. 2020 Oct 21. doi: 10.1016/j.bbrc.2020.10.045.

26. Young BE, Fong SW, Chan YH, Mak TM, Ang LW, Anderson DE, Lee CY, Amrun SN, Lee B, Goh YS, Su YC. Effects of a major deletion in the SARS-CoV-2 genome on the severity of infection and the inflammatory response: an observational cohort study. The Lancet. 2020 Aug 29;396(10251):603-11.

27. Habel JR, Nguyen TH, van de Sandt CE, Juno JA, Chaurasia P, Wragg K, Koutsakos M, Hensen L, Jia X, Chua B, Zhang W. Suboptimal SARS-CoV-2- specific CD8+ T cell response associated with the prominent HLA-A* 02: 01 phenotype. Proceedings of the National Academy of Sciences. 2020 Sep 29;117(39):24384-91.

28. Zhang JY, Wang XM, Xing X, Xu Z, Zhang C, Song JW, Fan X, Xia P, Fu JL, Wang SY, $\mathrm{Xu}$ RN. Single-cell landscape of immunological responses in patients with COVID-19. Nature immunology. 2020 Sep;21(9):1107-18.

29. De Biasi S, Meschiari M, Gibellini L, Bellinazzi C, Borella R, Fidanza L, Gozzi L, Iannone A, Tartaro DL, Mattioli M, Paolini A. Marked T cell activation, senescence, exhaustion and skewing towards TH17 in patients with COVID-19 pneumonia. Nature communications. $2020 \mathrm{Jul} \mathrm{6;11(1):1-7.}$

30. Focosi D, Bestagno M, Burrone O, Petrini M. CD57+ T lymphocytes and functional immune deficiency. J Leukoc Biol. 2010 Jan;87(1):107-16. doi: 10.1189/jlb.0809566. Epub 2009 Oct 30. Erratum in: J Leukoc Biol. 2010 Jun;87(6):1167. PMID: 19880576.

31. Chattopadhyay PK, Betts MR, Price DA, Gostick E, Horton H, Roederer M, De Rosa SC. The cytolytic enzymes granyzme A, granzyme B, and perforin: expression patterns, cell distribution, and their relationship to cell maturity and bright CD57 expression. J Leukoc Biol. 2009 Jan;85(1):88-97. doi: 10.1189/jlb.0208107. Epub 2008 Oct 10. PMID: 18820174; PMCID: PMC2638730.

32. Klebanoff CA, Scott CD, Leonardi AJ, et al. Memory T cell-driven differentiation of naive cells impairs adoptive immunotherapy. J Clin Invest. (2016) 126(1):318-334.

doi:10.1172/JCI81217 
33. O'Connell J. Fas ligand and the fate of antitumour cytotoxic T lymphocytes. Immunology. 2002 Mar;105(3):263-6. doi: 10.1046/j.1365-2567.2002.01379.x.

34. Cruz AC, Ramaswamy M, Ouyang C, Klebanoff CA, Sengupta P, Yamamoto TN, Meylan F, Thomas SK, Richoz N, Eil R, Price S, Casellas R, Rao VK, Lippincott-Schwartz J, Restifo NP, Siegel RM. Fas/CD95 prevents autoimmunity independently of lipid raft localization and efficient apoptosis induction. Nat Commun. 2016 Dec 23;7:13895. doi: $10.1038 /$ ncomms 13895 .

35. Ouyang W, Liao W, Luo CT, Yin N, Huse M, Kim MV, Peng M, Chan P, Ma Q, Mo Y, Meijer D, Zhao K, Rudensky AY, Atwal G, Zhang MQ, Li MO. Novel Foxo1-dependent transcriptional programs control T(reg) cell function. Nature. 2012 Nov 22;491(7425):554-9. doi: 10.1038/nature11581. Epub 2012 Nov 7. PMID: 23135404; PMCID: PMC3771531.

36. Kerdiles YM, Stone EL, Beisner DR, McGargill MA, Ch'en IL, Stockmann C, Katayama $\mathrm{CD}$, Hedrick SM. Foxo transcription factors control regulatory T cell development and function. Immunity. 2010 Dec 14;33(6):890-904. doi: 10.1016/j.immuni.2010.12.002. Erratum in: Immunity. 2011 Jan 28;34(1):135. Beisner, Daniel L [corrected to Beisner, Daniel R]. PMID: 21167754; PMCID: PMC3034255.

37. Crompton JG, Sukumar M, Roychoudhuri R, et al. Akt inhibition enhances expansion of potent tumor-specific lymphocytes with memory cell characteristics. Cancer Res. (2015) 75(2):296-305. doi:10.1158/0008-5472.CAN-14-2277

38. Klebanoff CA, Crompton JG, Leonardi AJ, et al. Inhibition of AKT signaling uncouples $\mathrm{T}$ cell differentiation from expansion for receptor-engineered adoptive immunotherapy. JCI Insight. (2017) 2(23):e95103. doi:10.1172/jci.insight.95103

39. Mathew D, Giles JR, Baxter AE, et al. Deep immune profiling of COVID-19 patients reveals distinct immunotypes with therapeutic implications. Science. 2020; eabc8511. doi:10.1126/science.abc8511

40. Fagone P, Ciurleo R, Lombardo SD, Iacobello C, Palermo CI, Shoenfeld Y, Bendtzen K, Bramanti P, Nicoletti F. Transcriptional landscape of SARS-CoV-2 infection dismantles pathogenic pathways activated by the virus, proposes unique sex-specific differences and predicts tailored therapeutic strategies. Autoimmun Rev. 2020 Jul;19(7):102571. doi: 10.1016/j.autrev.2020.102571.

41. Somanath PR. Is targeting Akt a viable option to treat advanced-stage COVID-19 patients? Am J Physiol Lung Cell Mol Physiol. 2020 Jul 1;319(1):L45-L47. doi: 10.1152/ajplung.00124.2020.

42. Weisberg E, Parent A, Yang PL, Sattler M, Liu Q, Liu Q, Wang J, Meng C, Buhrlage SJ, Gray N, Griffin JD. Repurposing of Kinase Inhibitors for Treatment of COVID-19. Pharm Res. 2020 Aug 10;37(9):167. doi: 10.1007/s11095-020-02851-7.

43. Ramaiah MJ. mTOR inhibition and p53 activation, microRNAs: The possible therapy against pandemic COVID-19. Gene Rep. 2020 Sep;20:100765. doi: 10.1016/j.genrep.2020.100765. Epub 2020 Jun 30. 
44. Nitulescu GM, Paunescu H, Moschos SA, Petrakis D, Nitulescu G, Ion GND, Spandidos DA, Nikolouzakis TK, Drakoulis N, Tsatsakis A. Comprehensive analysis of drugs to treat SARS-CoV-2 infection: Mechanistic insights into current COVID-19 therapies (Review). Int J Mol Med. 2020 Aug;46(2):467-488. doi: 10.3892/ijmm.2020.4608.

45. Sorbera LA, Graul AI, Dulsat C. Taking aim at a fast-moving target: targets to watch for SARS-CoV-2 and COVID-19. Drugs of the Future. 2020 Apr 1;45(4):239-44.

46. Lee JS, Shin EC. The type I interferon response in COVID-19: implications for treatment. Nat Rev Immunol. 2020 Oct;20(10):585-586. doi: 10.1038/s41577-020-00429-3. PMID: 32788708 .

47. Lee JS, Park S, Jeong HW, Ahn JY, Choi SJ, Lee H, Choi B, Nam SK, Sa M, Kwon JS, Jeong SJ, Lee HK, Park SH, Park SH, Choi JY, Kim SH, Jung I, Shin EC.

Immunophenotyping of COVID-19 and influenza highlights the role of type I interferons in development of severe COVID-19. Sci Immunol. 2020 Jul 10;5(49):eabd1554. doi: 10.1126/sciimmunol.abd1554. PMID: 32651212; PMCID: PMC7402635.

48. Hadjadj J, Yatim N, Barnabei L, Corneau A, Boussier J, Smith N, Péré H, Charbit B, Bondet V, Chenevier-Gobeaux C, Breillat P, Carlier N, Gauzit R, Morbieu C, Pène F, Marin N, Roche N, Szwebel TA, Merkling SH, Treluyer JM, Veyer D, Mouthon L, Blanc C, Tharaux PL, Rozenberg F, Fischer A, Duffy D, Rieux-Laucat F, Kernéis S, Terrier B. Impaired type I interferon activity and inflammatory responses in severe COVID-19 patients. Science. 2020 Aug 7;369(6504):718-724. doi: 10.1126/science.abc6027. Epub 2020 Jul 13.

49. Wang N, Zhan Y, Zhu L, Hou Z, Liu F, Song P, Qiu F, Wang X, Zou X, Wan D, Qian X, Wang S, Guo Y, Yu H, Cui M, Tong G, Xu Y, Zheng Z, Lu Y, Hong P. Retrospective Multicenter Cohort Study Shows Early Interferon Therapy Is Associated with Favorable Clinical Responses in COVID-19 Patients. Cell Host Microbe. 2020 Sep 9;28(3):455-464.e2. doi: 10.1016/j.chom.2020.07.005. Epub 2020 Jul 18. PMID: 32707096; PMCID: PMC7368656.

50. Bastard P, Rosen LB, Zhang Q, Michailidis E, Hoffmann HH, Zhang Y, Dorgham K, Philippot Q, Rosain J, Béziat V, Manry J, Shaw E, Haljasmägi L, Peterson P, Lorenzo L, Bizien L, Trouillet-Assant S, Dobbs K, de Jesus AA, Belot A, Kallaste A, Catherinot E, Tandjaoui-Lambiotte Y, Le Pen J, Kerner G, Bigio B, Seeleuthner Y, Yang R, Bolze A, Spaan AN, Delmonte OM, Abers MS, Aiuti A, Casari G, Lampasona V, Piemonti L, Ciceri F, Bilguvar K, Lifton RP, Vasse M, Smadja DM, Migaud M, Hadjadj J, Terrier B, Duffy D, Quintana-Murci L, van de Beek D, Roussel L, Vinh DC, Tangye SG, Haerynck F, Dalmau D, Martinez-Picado J, Brodin P, Nussenzweig MC, Boisson-Dupuis S, Rodríguez-Gallego C, Vogt G, Mogensen TH, Oler AJ, Gu J, Burbelo PD, Cohen JI, Biondi A, Bettini LR, D'Angio M, Bonfanti P, Rossignol P, Mayaux J, Rieux-Laucat F, Husebye ES, Fusco F, Ursini MV, Imberti L, Sottini A, Paghera S, Quiros-Roldan E, Rossi C, Castagnoli R, Montagna D, Licari A, Marseglia GL, Duval X, Ghosn J; HGID Lab; NIAID-USUHS Immune Response to COVID Group; COVID Clinicians; COVID-STORM Clinicians; Imagine COVID Group; French COVID Cohort Study Group; Milieu Intérieur Consortium; CoV-Contact Cohort; Amsterdam UMC Covid-19 Biobank; COVID Human Genetic Effort, Tsang JS, GoldbachMansky R, Kisand K, Lionakis MS, Puel A, Zhang SY, Holland SM, Gorochov G, Jouanguy E, Rice CM, Cobat A, Notarangelo LD, Abel L, Su HC, Casanova JL. Autoantibodies against 
type I IFNs in patients with life-threatening COVID-19. Science. 2020 Oct

23;370(6515):eabd4585. doi: 10.1126/science.abd4585.

51. Zhang Q, Bastard P, Liu Z, Le Pen J, Moncada-Velez M, Chen J, Ogishi M, Sabli IK, Hodeib S, Korol C, Rosain J. Inborn errors of type I IFN immunity in patients with lifethreatening COVID-19. Science. 2020 Sep 24.

52. Yang J, Zhong M, Zhang E, et al. Broad phenotypic alterations and potential dysfunctions of lymphocytes in COVID-19 recovered individuals. MedRxiv. (2020)

doi:10.1101/2020.07.01.20144030

53. Yamamoto TN, Lee PH, Vodnala SK, Gurusamy D, Kishton RJ, Yu Z, Eidizadeh A, Eil R, Fioravanti J, Gattinoni L, Kochenderfer JN, Fry TJ, Aksoy BA, Hammerbacher JE, Cruz AC, Siegel RM, Restifo NP, Klebanoff CA. T cells genetically engineered to overcome death signaling enhance adoptive cancer immunotherapy. J Clin Invest. 2019 Feb 25;129(4):15511565. doi: 10.1172/JCI121491.

54. Kalfaoglu Bahire, Almeida-Santos José, Tye Chanidapa Adele, Satou Yorifumi, Ono Masahiro. T-Cell Hyperactivation and Paralysis in Severe COVID-19 Infection Revealed by Single-Cell Analysis. Frontiers in Immunology. (2020)

http://doi.org/10.3389/fimmu.2020.589380

55. Lutz C, Maher L, Lee C, Kang W. COVID-19 preclinical models: human angiotensinconverting enzyme 2 transgenic mice. Hum Genomics. 2020 Jun 4;14(1):20. doi: 10.1186/s40246-020-00272-6. PMID: 32498696; PMCID: PMC7269898.

56. Temesgen Z, Assi M, Vergidis P, et al. First Clinical Use of Lenzilumab to Neutralize GM-CSF in Patients with Severe COVID-19 Pneumonia. Medrxiv (2020) $10.1101 / 2020.06 .08 .20125369$.

57. Cox MJ, Kuhlmann CJ, Sterner RM, et al. Improved Anti-Tumor Response of Chimeric Antigen Receptor T Cell (CART) Therapy after GM-CSF Inhibition Is Mechanistically Supported By a Novel Direct Interaction of GM-CSF with Activated Carts. Blood (2019) 134 (Supplement_1): 3868. doi.org/10.1182/blood-2019-129349

58. Yamada A, Arakaki R, Saito M, Kudo Y, Ishimaru N. Dual Role of Fas/FasL-Mediated Signal in Peripheral Immune Tolerance. Front Immunol. 2017 Apr 5;8:403. doi: 10.3389/fimmu.2017.00403.

59. Woodruff MC, Ramonell RP, Nguyen DC, Cashman KS, Saini AS, Haddad NS, Ley AM, Kyu S, Howell JC, Ozturk T, Lee S, Suryadevara N, Case JB, Bugrovsky R, Chen W, Estrada J, Morrison-Porter A, Derrico A, Anam FA, Sharma M, Wu HM, Le SN, Jenks SA, Tipton CM, Staitieh B, Daiss JL, Ghosn E, Diamond MS, Carnahan RH, Crowe JE Jr, Hu WT, Lee FE, Sanz I. Extrafollicular B cell responses correlate with neutralizing antibodies and morbidity in COVID-19. Nat Immunol. 2020 Oct 7. doi: 10.1038/s41590-020-00814-z.

60. Jenks SA, Cashman KS, Zumaquero E, Marigorta UM, Patel AV, Wang X, Tomar D, Woodruff MC, Simon Z, Bugrovsky R, Blalock EL, Scharer CD, Tipton CM, Wei C, Lim SS, Petri M, Niewold TB, Anolik JH, Gibson G, Lee FE, Boss JM, Lund FE, Sanz I. Distinct Effector B Cells Induced by Unregulated Toll-like Receptor 7 Contribute to Pathogenic 
Responses in Systemic Lupus Erythematosus. Immunity. 2018 Oct 16;49(4):725-739.e6. doi: 10.1016/j.immuni.2018.08.015. Erratum in: Immunity. 2020 Jan 14;52(1):203. PMID: 30314758; PMCID: PMC6217820.

61. Li Q, Yan Y, Liu J, Huang X, Zhang X, Kirschning C, Xu HC, Lang PA, Dittmer U, Zhang E, Lu M. Toll-Like Receptor 7 Activation Enhances CD8+ T Cell Effector Functions by Promoting Cellular Glycolysis. Front Immunol. 2019 Sep 12;10:2191. doi: 10.3389/fimmu.2019.02191. 